\title{
STUDI EKSPERIMEN MENGENAI SUB-SUB POLA ALIRAN STRATIFIED PADA ALIRAN DUA FASA SEARAH BERDASAR FLUKTUASI BEDA TEKANAN PADA PIPA HORISONTAL
}

\author{
Rianto Wibowo \\ Program Studi Teknik Mesin, Universitas Muria Kudus \\ Gondang Manis, Bae, Kudus \\ Email: riantowibowo_umk@yahoo.com \\ Akhmad Zidni Hudaya \\ Program Studi Teknik Mesin, Universitas Muria Kudus \\ Gondang Manis, Bae, Kudus \\ Masruki Kabib \\ Program Studi Teknik Mesin, Universitas Muria Kudus \\ Gondang Manis, Bae, Kudus
}

\begin{abstract}
ABSTRAK
Keakuratan perhitungan rekayasa untuk aliran dua fasa sangat tergantung dari model dan karakteristik spesifik dari peta pola aliran tersebut, sehingga penentuan pola-pola aliran dan sub-sub pola aliran menjadi sangat penting. Pada tataran aplikasi, pengkajian pola aliran stratified menggunakan metode analisis statistik dengan fluktuasi tekanan sangat cocok diaplikasikan pada industri karena tidak ada persyaratan untuk bahan pipa, khususnya dimana sensor tekanan akan dipasang. Hal ini juga akan menghapus segala keterbatasan pengkajian pola aliran stratified dengan menggunakan metode konduktansi. Tujuan dari studi ini adalah mengklasifikasi sub-sub pola aliran stratified air-udara pada pipa horizontal berdasarkan hasil pengukuran sinyal keluaran sensor tekanan. Metodologi yang digunakan adalah kaji eksperimental visualisasi dan pengukuran fluktuasi beda tekanan. Pipa acrylic transparan dengan diameter dalam $26 \mathrm{~mm}$ dan panjang $10 \mathrm{~m}$ digunakan agar sub-sub pola aliran stratified dapat diamati secara visual menggunakan kamera video kecepatan tinggi. Untuk mengukur fluktuasi beda tekanan dilakukan dengan pengukuran tekanan diferensial pada seksi uji dengan posisi tap 180 D dan 210 D. Hasil penelitian menunjukan visualisasi sub-sub pola aliran stratified yang diamati masih cukup sulit dideteksi jika hanya dengan kehadiran fluktuasi beda tekanan saja.
\end{abstract}

Kata kunci: aliran stratified, pengukuran tekanan, sub-sub pola aliran, visualisasi.

\begin{abstract}
The accuracy of engineering calculations for two-phase flow is highly dependent on the specific characteristics of the model and map the flow pattern, so that the determination of flow patterns and subflow patterns are very important. At the application level, assessment stratified flow patterns using statistical analysis methods with suitable pressure fluctuations applied to the industry because there is no requirement for the pipe material, especially where the pressure sensor will be installed. It also will remove all the limitations of the study stratified flow pattern using conductance method. The aim of this study was to classify the sub-stratified flow pattern of water-air on a horizontal pipe based on the measurement of the pressure sensor output signal. The methodology used is studied experimental visualization and measurement of fluctuations in pressure difference. Transparent acrylic pipe with an inner diameter of $26 \mathrm{~mm}$ and a length of $10 \mathrm{~m}$ is used so that the sub-stratified flow pattern can be observed visually using a high speed video camera. To measure the pressure difference fluctuation is done by measuring the differential pressure in the test section with tap positions $180 \mathrm{D}$ and $210 \mathrm{D}$. The results showed the visualization sub-stratified flow pattern observed is still quite difficult to detect if only the presence of fluctuations in the pressure difference alone.
\end{abstract}

Keywords: stratified flow, pressure measurement, sub-flow patterns, visualization. 


\section{PENDAHULUAN}

Salah satu permasalahan yang sangat penting pada transportasi fluida aliran dua fasa di dalam pipa adalah kerugian tekanan akibat gesekan. Akan tetapi sebelum mengkaitkan dengan kerugian tekanan, pada perencanaan fasilitas aliran dua fasa perlu mempertimbangkan pola aliran karena pola aliran tertentu dapat menghasilkan efisiensi produksi yang lebih tinggi atau pula dapat membahayakan bagi instalasi yang ada jika dibanding dengan pola aliran lain.

Pola aliran dapat diketahui melalui pengamatan visual langsung menggunakan pipa transparan, fotografi menggunakan sinar $X$ dan atau analisa sinyal menggunakan metode konduktansi $[1,2]$ dan metode pegukuran tekanan [3,4]. Pada kenyataannya, tidak ada satupun metode identifikasi yang memadai dalam semua situasi untuk menentukan pola aliran dua fasa akan tetapi kombinasi dari metodemetode tersebut harus digunakan dalam kondisi yang tepat. Pada tataran aplikasi, pengkajian pola aliran stratified menggunakan metode analisis statistik dengan fluktuasi tekanan sangat cocok diaplikasikan pada industri karena tidak ada persyaratan untuk bahan pipa, khususnya dimana sensor tekanan akan dipasang. Hal ini juga akan menghapus segala keterbatasan pengkajian pola aliran stratified dengan menggunakan metode konduktansi.

Tujuan dari studi ini adalah mengklasifikasi sub-sub pola aliran stratified air-udara pada pipa horizontal berdasarkan hasil pengukuran sinyal keluaran sensor tekanan dikombinasikan dengan metode pengamatan visual langsung menggunakan pipa transparan.

\section{METODE PENELITIAN}

Metode yang digunakan dalam penelitian ini adalah kaji eksperimental visualisasi dan pengukuran fluktuasi beda tekanan seperti yang terlihat pada gambar 1. Pipa acrylic transparan dengan diameter dalam $26 \mathrm{~mm}$ dan panjang $10 \mathrm{~m}$ digunakan agar sub-sub pola aliran stratified dapat diamati secara visual menggunakan kamera video kecepatan tinggi. Untuk mengukur fluktuasi beda tekanan dilakukan dengan pengukuran tekanan diferensial dengan posisi tap $180 \mathrm{D}$ dan 210D. Sinyal dari sensor tekanan dikuatkan dengan amplifier, kemudian diubah oleh Analog to Digital Converter agar dapat dibaca komputer menjadi data sinyal tekanan dalam rangkaian waktu. Selanjutnya sub-sub pola aliran stratified diklasifikasian berdasarkan pengamatan visual dan data sinyal tekanan dalam rangkaian waktu.

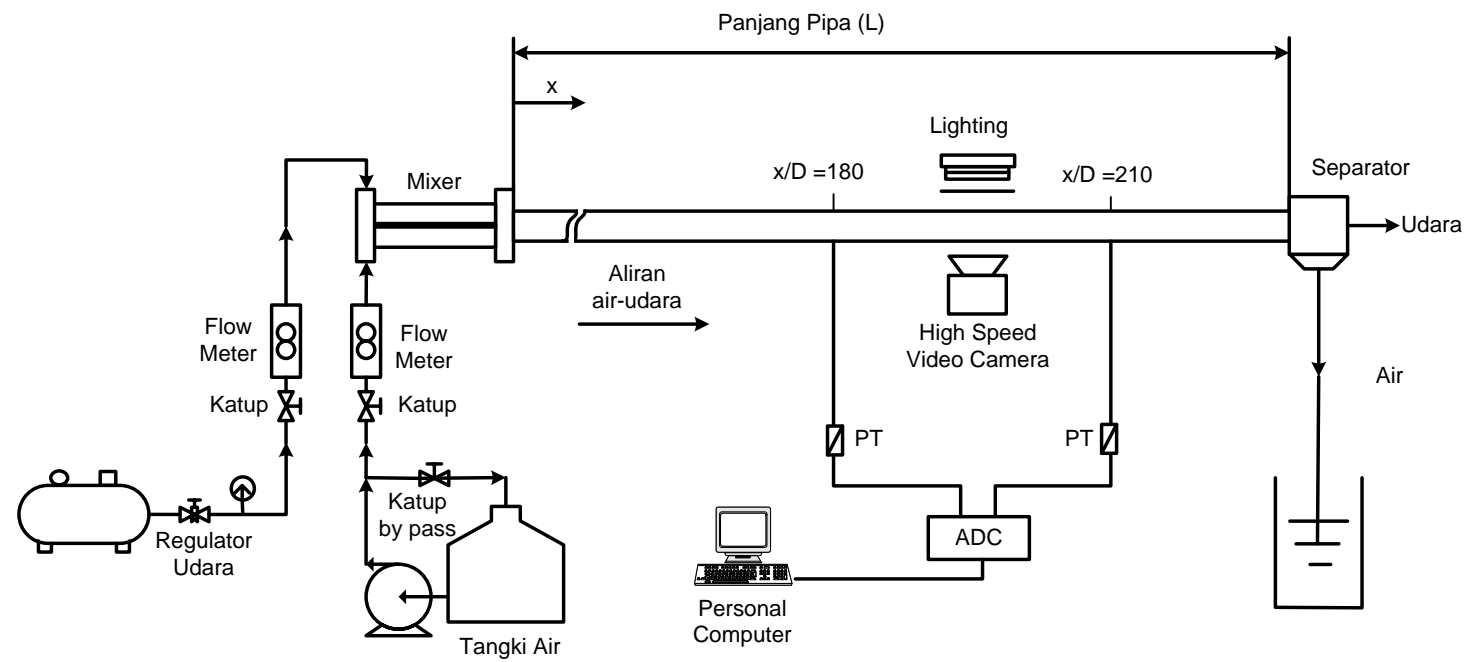

Gambar 1. Skema Alat Penelitian

\section{HASIL DAN PEMBAHASAN}

Pola aliran stratified secara detail dibagi menjadi subdaerah-subdaerah berdasarkan struktur antarmuka. Namun, Sebagian besar peneliti membagi aliran stratified menjadi dua subdaerah yaitu stratified smooth dan stratified wavy. Sedangkan stratified wavy dapat dibagi lagi menjadi sub-sub daerah yaitu two dimensional wave, roll wave dan atomization.

Sub daerah stratified smooth terjadi pada kecepatan superfisial air dan udara yang rendah dimana antarmuka antara fasa cair dan gas tampak datar dan tidak ada gangguan. Pada gambar 1. memperlihatkan contoh visualisasi dan sinyal beda tekanan aliran stratified smooth pada kecepatan superfisial air, $\mathrm{J}_{\mathrm{L}}=$ $0,025 \mathrm{~m} / \mathrm{s}$ dan kecepatan superfisial udara, $\mathrm{J}_{\mathrm{G}}=1,88 \mathrm{~m} / \mathrm{s}$. 


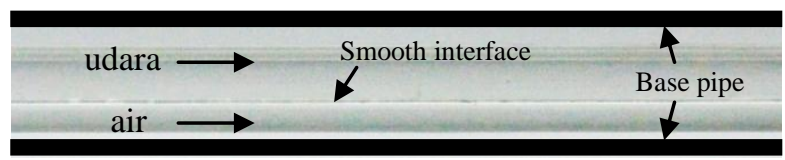

(a)

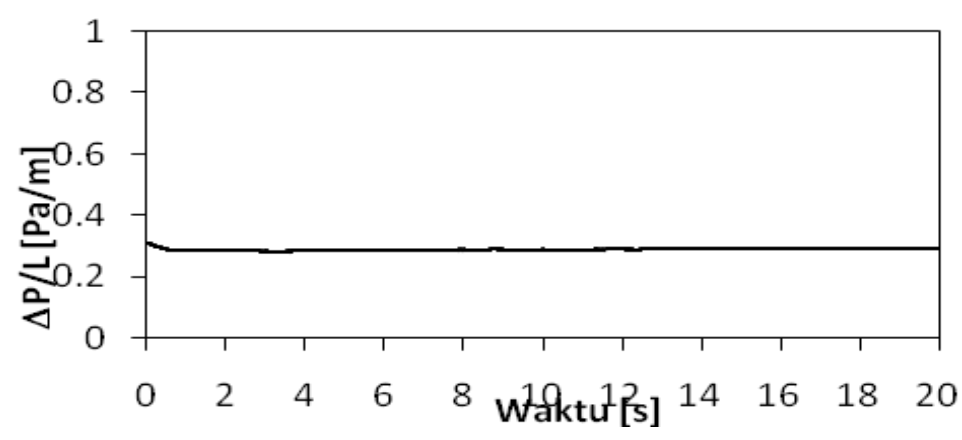

(b)

\section{Gambar 1. Contoh Visualisasi Dan Sinyal Beda Tekanan Aliran Stratified Smooth}

Jika kecepatan gas pada aliran stratified smooth dinaikkan, maka pada antarmuka cair dan gas akan terjadi gelombang yang mempunyai amplitudo kecil dan panjang gelombang pendek serta bentuk gelombang yang teratur. Sub-daerah aliran stratified ini disebut two dimensional wave (2D wave).
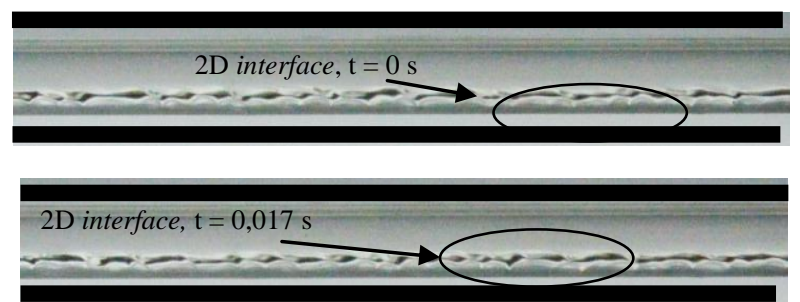

(a)

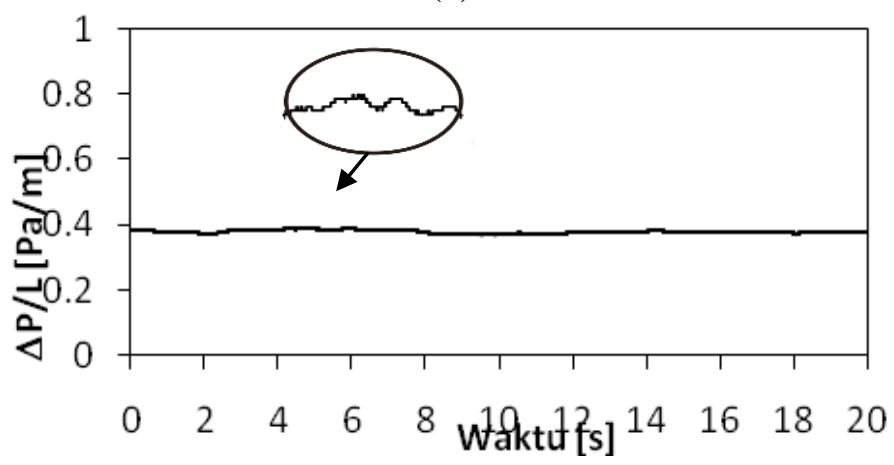

(b)

Gambar 2. Visualisasi Dan Sinyal Beda Tekanan Aliran Stratified Gelombang $2 D\left(J_{\mathrm{L}}=0,025 \mathrm{~m} / \mathrm{s}\right.$ $\operatorname{Dan} \mathbf{J}_{\mathrm{G}}=\mathbf{3 , 7 7} \mathrm{m} / \mathrm{s}$ )

Pada gambar 2, memperlihatkan contoh visualisasi dan sinyal beda tekanan aliran stratified gelombang $2 D$ pada kecepatan superfisial air, $\mathrm{J}_{\mathrm{L}}=0,025 \mathrm{~m} / \mathrm{s}$ dan kecepatan superfisial udara, $\mathrm{J}_{\mathrm{G}}=3,77$ $\mathrm{m} / \mathrm{s}$. Pada sub-daerah ini, sinyal beda tekanan tidak tampak mengalami fluktuasi meskipun pada visualisasi tampak antarmuka yang bergelombang teratur. Hal ini menjelaskan bahwa pada sub-daerah ini, gas tidak mengalami proses kompresi dan fluktuasi tinggi gelombang yang kecil kurang terukur oleh sensor tekanan. 


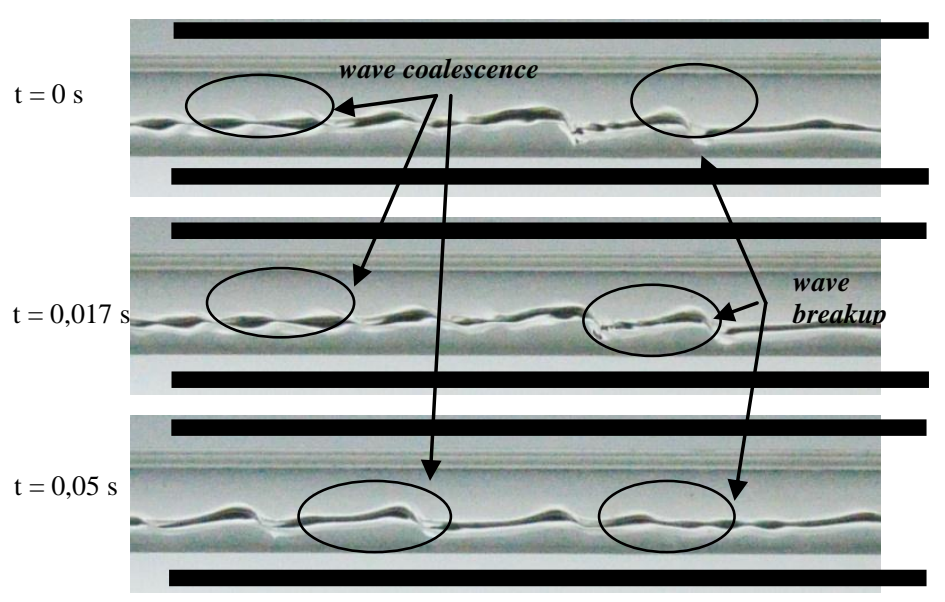

(a)

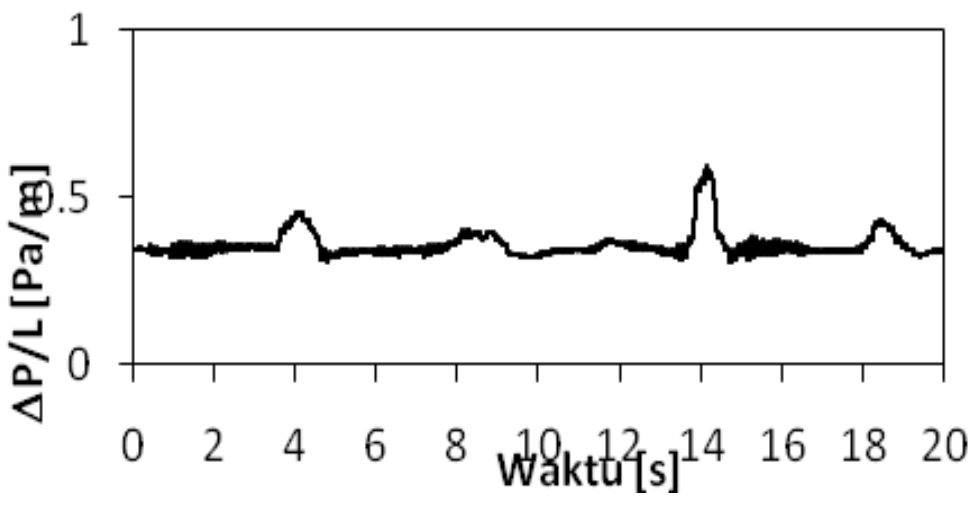

(b)

\section{Gambar 3. Contoh Visualisasi Dan Sinyal Beda Tekanan Aliran Roll Wave $\left(\mathbf{J}_{\mathrm{L}}=\mathbf{0 , 0 5} \mathrm{m} / \mathrm{s}\right.$ dan $\left.\mathbf{J}_{\mathrm{G}}=3,77 \mathrm{~m} / \mathrm{s}\right)$}

Pada kecepatan gas yang cukup tinggi, pada antarmuka cairan dan gas akan terlihat panjang gelombang dan amplitudo yang besar serta bentuk gelombang yang tidak teratur. Pada kondisi ini mulai tampak adanya fluktuasi tekanan yanng cukup besar. Sub-daerah ini disebut roll wave dan merupakan inisisasi terbentuknya aliran slug.

Ketika fasa gas mengalami percepatan maka tekanan gas di atas puncak gelombang akan mengalami penurunan akibat efek Bernoulli sehingga antarmuka akan semakin terangkat ke atas dan amplitudo akan semakin besar. Akan tetapi, kenaikan gelombang ini akan dihalangi oleh gravitasi. Jika pengaruh dari percepatan lebih besar dari efek gravitasi maka amplitudo semakin besar maka akan membentuk pola aliran slug. Gambar 3. memperlihatkan contoh visualisasi dan sinyal beda tekanan aliran stratified roll wave pada kecepatan superfisial air, $\mathrm{J}_{\mathrm{L}}=0,05 \mathrm{~m} / \mathrm{s}$ dan kecepatan superfisial udara, $\mathrm{J}_{\mathrm{G}}=3,77$ $\mathrm{m} / \mathrm{s}$. Pada visualisasi terlihat juga bahwa beberapa gelombang yang lebih cepat menabrak gelombang yang lebih lambat dan menyebabkan gelombang-gelombang tersebut bergabung. Fenomena ini disebut wave coalescence. Sebaliknya gelombang besar yag pecah menjadi gelombang yang lebih kecil disebut wave break-up. 

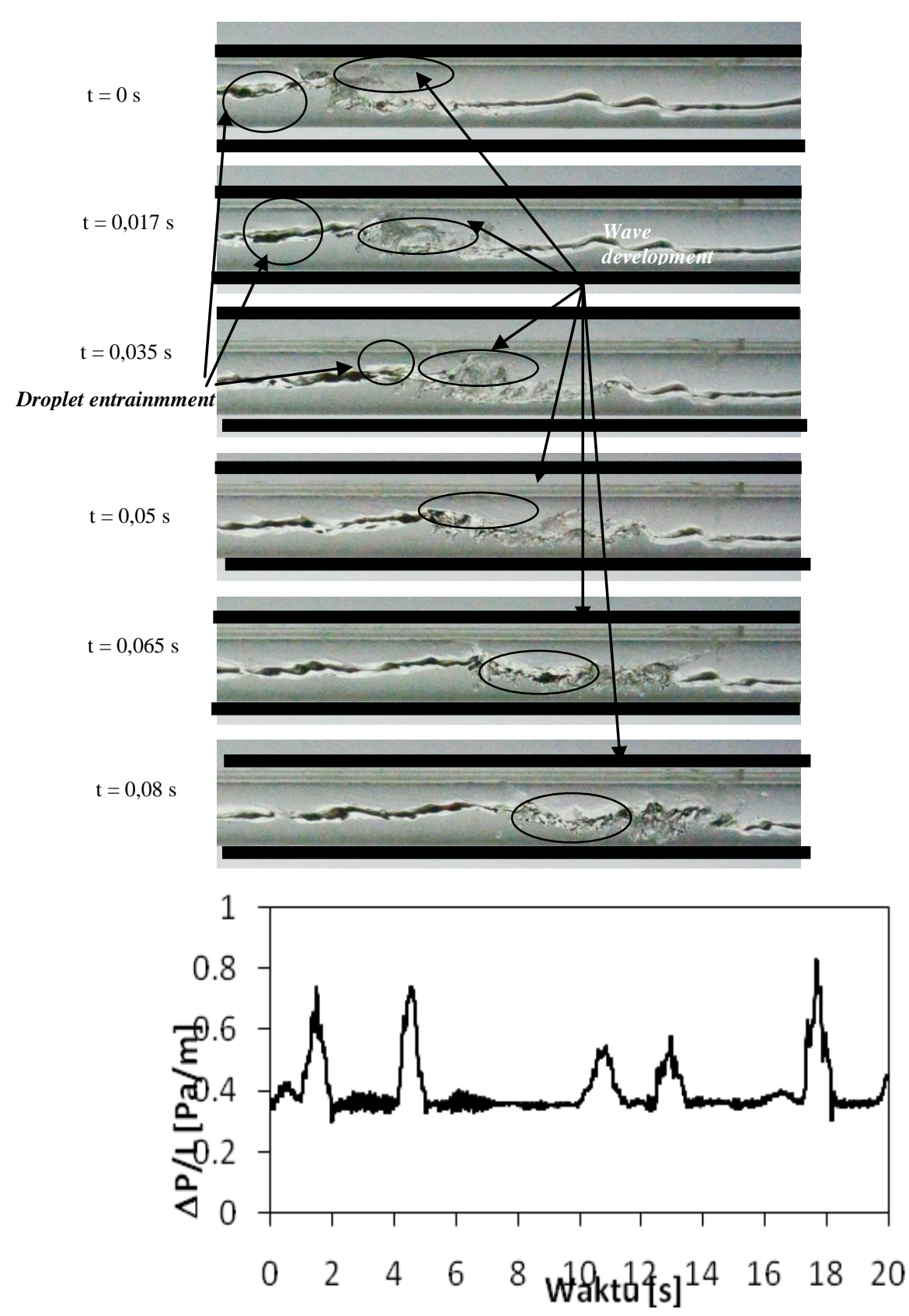

Gambar 4. Contoh Visualisasi Dan Sinyal Beda Tekanan Sub Daerah Atomization $\left(\mathbf{J}_{\mathrm{L}}=\mathbf{0 , 0 7 5} \mathrm{m} / \mathrm{s}\right.$ dan $\left.\mathbf{J}_{\mathrm{G}}=3,77 \mathrm{~m} / \mathrm{s}\right)$

Gambar 4. memperlihatkan contoh visualisasi dan sinyal beda tekanan sub-daerah atomization pada kecepatan superfisial air, $\mathrm{J}_{\mathrm{L}}=0,075 \mathrm{~m} / \mathrm{s}$ dan kecepatan superfisial udara, $\mathrm{J}_{\mathrm{G}}=3,77 \mathrm{~m} / \mathrm{s}$. Pada kecepatan gas yang sangat tinggi, atomisasi terjadi melalui pelepasan wavelet dari puncak gelombang karena adanya gaya geser aliran gas. Sub-daerah ini disebut atomization.

Gambar 5 menunjukkan perbandingan pola aliran yang diamati dengan peta pola aliran yang sudah ada sebagai bahan referensi [1,2]. Peta pola aliran yang dipilih sebagai perbandingan adalah peta pola aliran yang umum digunakan. 


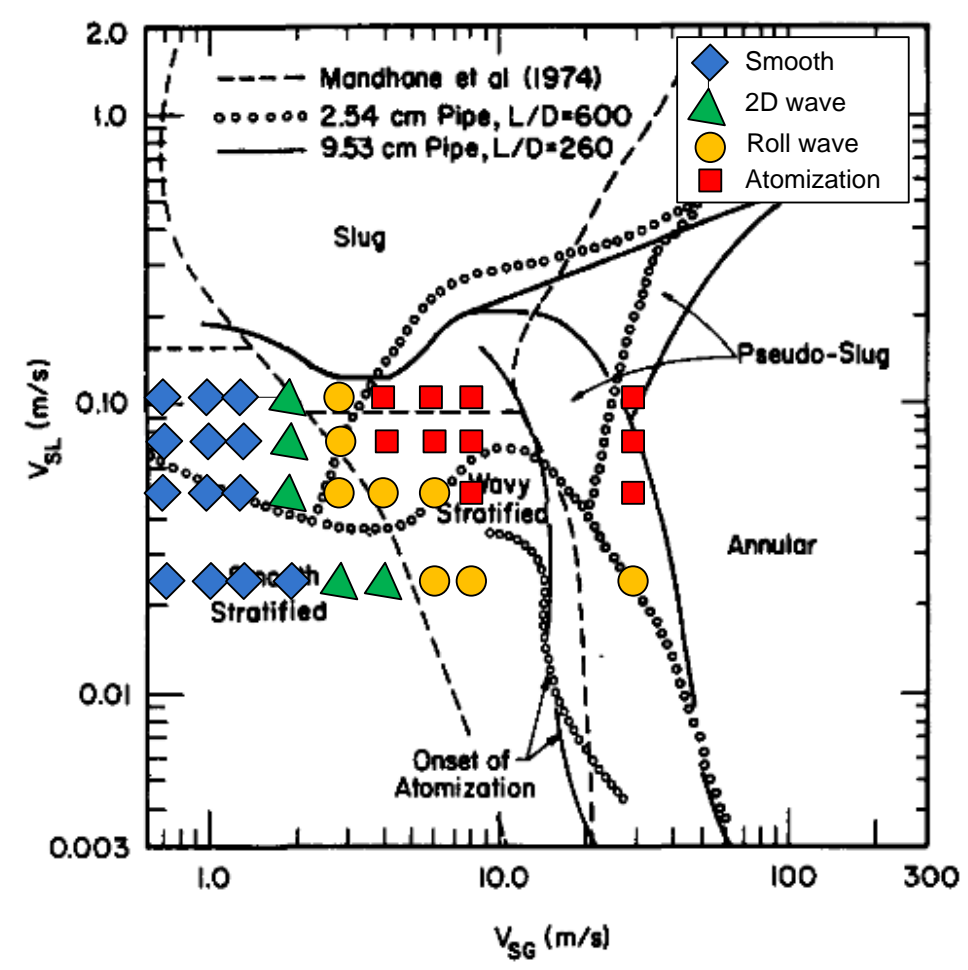

Gambar 5. Perbandingan Pola Aliran Yang Diamati Dengan Peta Mandhane[1] Dan Peta Lin \& Hanratty(2]

\section{KESIMPULAN}

1) Pola aliran stratified yang berhasil diamati secara visual dibagi menjadi sub-sub daerah yang meliputi stratified smooth, two dimensional wave, Roll wave dan atomization.

2) Visualisasi sub-sub pola aliran stratified yang diamati masih cukup sulit dideteksi jika hanya menggunakan fluktuasi beda tekanan saja. Hal ni disebabkan karena sinyal beda tekanan tidak langsung menggambarkan morfologi pola aliran.

\section{UCAPAN TERIMAKASIH}

Penelitian ini didanai Hibah Pekerti, Kementrian Riset Teknologi dan Pendidikan Tinggi berdasarkan Keputusan Direktur Penelitian dan Pengabdian Kepada Masyarakat No. 0100/E5.1/2015.

\section{DAFTAR PUSTAKA}

[1] Lin, P.Y. and Hanratty, T.J., 1987, Effect of Pipe Diameter on flow patterns for air-water flow in horizontal. Int. J. Multiphase Flow, Vol. 13, No. 4 ,pp. 549-563.

[2] Mandhane, J.M., Gregory, G.A., Aziz, K., 1974, A flow pattern map for gas-liquid flow in horizontal and inclined pipes, International Journal of Multiphase Flow 1 pp. 537-553.

[3] Spedding, P. L. and Nguyen, V.T., 1979, Regime Map for Air Water Two-Phase Flow, Chemical Engineering Science Vol 35, pp. 779-793

[4] Spedding, P. L. and D.R. Spence, 1993, Flow Regimes in Two-Phase Gas-liquid Flow, Int. J. of Multiphase Flow, Vol. 19, No. 2, pp. 217-225 